\title{
Pregnancy Outcome in Uterine Anomalies
}

\author{
${ }^{1} \mathrm{R}$ Nagarathnamma, ${ }^{2}$ Thingujam James, ${ }^{3}$ Nagendra Prasad
}

\begin{abstract}
Maternal with congenitial anomalies are known to have higher incidence of infertility, intrauterine growth restriction, fetal malposition, preterm labor, preterm premature rupture of membrane and increased cesaerean section rate.
\end{abstract}

Study Design: This is retrospective study, the pregnancies with uterine anomaly confirmed by ultrasound between Jan 2016 to jan 2017 at our hospital was taken and its outcome is observed.

Reults: The majority of preterm delivery in our study are mainly associated with septate and bicornuate uterus. Cesaerean section comprised of $80 \%$ and its major indication is due to fetal malpresentation (breech) .Thus Pregnancy outcomes of individual depending on the type of uterine anomalies.

Keywords: Malpresentation, Preterm birth, Preterm premature rupture of the membranes, Uterine anomalies.

How to cite this article: Nagarathnamma R, James $T$, Prasad N. Pregnancy Outcome in Uterine Anomalies. J Med Sci 2017;3(1):31-33.

\section{Source of support: Nil}

Conflict of interest: None

\section{INTRODUCTION}

Maldevelopment of Müllerian ducts occurs in a variety of forms, and each anomaly is distinctive. Various classifications of uterine malformation have been proposed. The one used by the American Fertility Society was established in 1988 (Fig. 1) based on the previous work of Bhuttram and Gibbons (1979). ${ }^{1}$ The classification is into groups according to the degree of failure of normal development with similar clinical manifestations, treatment, and possible prognosis for their reproductive performance. ${ }^{2}$ The four principal deformities that arise from defective Müllerian ducts (embryological ducts) steps are:

1. Agenesis of both ducts, either focally or along the entire duct length.

2. Unilateral maturation of one Mullerian duct with incomplete or absent development of the opposite side.

\footnotetext{
${ }^{1}$ Professor and Head, ${ }^{2}$ Postgraduate Student, ${ }^{3}$ Associate Professor

${ }^{1-3}$ Department of Obstetrics and Gynaecology, RajaRajeswari Medical College and Hospital, Bengaluru, Karnataka, India

Corresponding Author: Thingujam James, Postgraduate Student Department of Obstetrics and Gynaecology, RajaRajeswari Medical College and Hospital, Bengaluru, Karnataka, India, e-mail: thjamboicha@gmail.com
}

3. Absent or faulty midline fusion of the ducts.

4. Defective canalization.

The relationship between uterine anomalies and adverse pregnancy outcomes in the third trimester is less well studied. Authors who have found an association between uterine anomalies and preterm birth say that diminished muscle mass, particularly in a unicornuate uterus, plays an important role in the mechanism of preterm delivery. ${ }^{3}$ Uterine malformations with pregnancy are often revealed at the time of the first sonographic examination in early pregnancy.

\section{MATERIALS AND METHODS}

In this retrospective study, we tried to estimate the relationship between congenital uterine anomalies and adverse pregnancy outcomes. Our study comprised all pregnancies ( $>27$ weeks of gestation age) with uterine anomalies confirmed by ultrasound, which underwent routine anatomic survey from January 2016 to January 2017 at our tertiary care center.

Gestational age was determined by the first day of the woman's last menstrual period (LMP). If the LMPestimated due date was consistent (i.e., 5 days in the 1st trimester, 14 days in the 2 nd trimester, and 21 days in the 3rd trimester) with the due date obtained from the first ultrasound, then the due date was not changed. If the due dates by LMP and first ultrasound were not consistent, then the ultrasound-obtained due date was used to define gestational age.

\section{RESULTS}

During 1 year, the total women with uterine anomalies are 10 (Table 1). It consists of four cases of arcuate uterus, three cases with bicornuate uterus, two cases of septate uterus, and one case of unicornuate uterus.

Table 2 shows that in four cases of arcuate uterus, two women had previous miscarriage, and one woman had children. A total of three women were diagnosed with bicornuate uterus, out of these two women have a child and one woman had previous miscarriage. In septate uterus, out of three women, two women had pervious miscarriage.

In bicornuate uterus groups, uterus, the rates of preterm $(66.6 \%)$ and two women had preterm premature rupture of the membranes (PPROM). Women with septate uterus had preterm delivery, out of which one woman had PPROM (Table 3). 


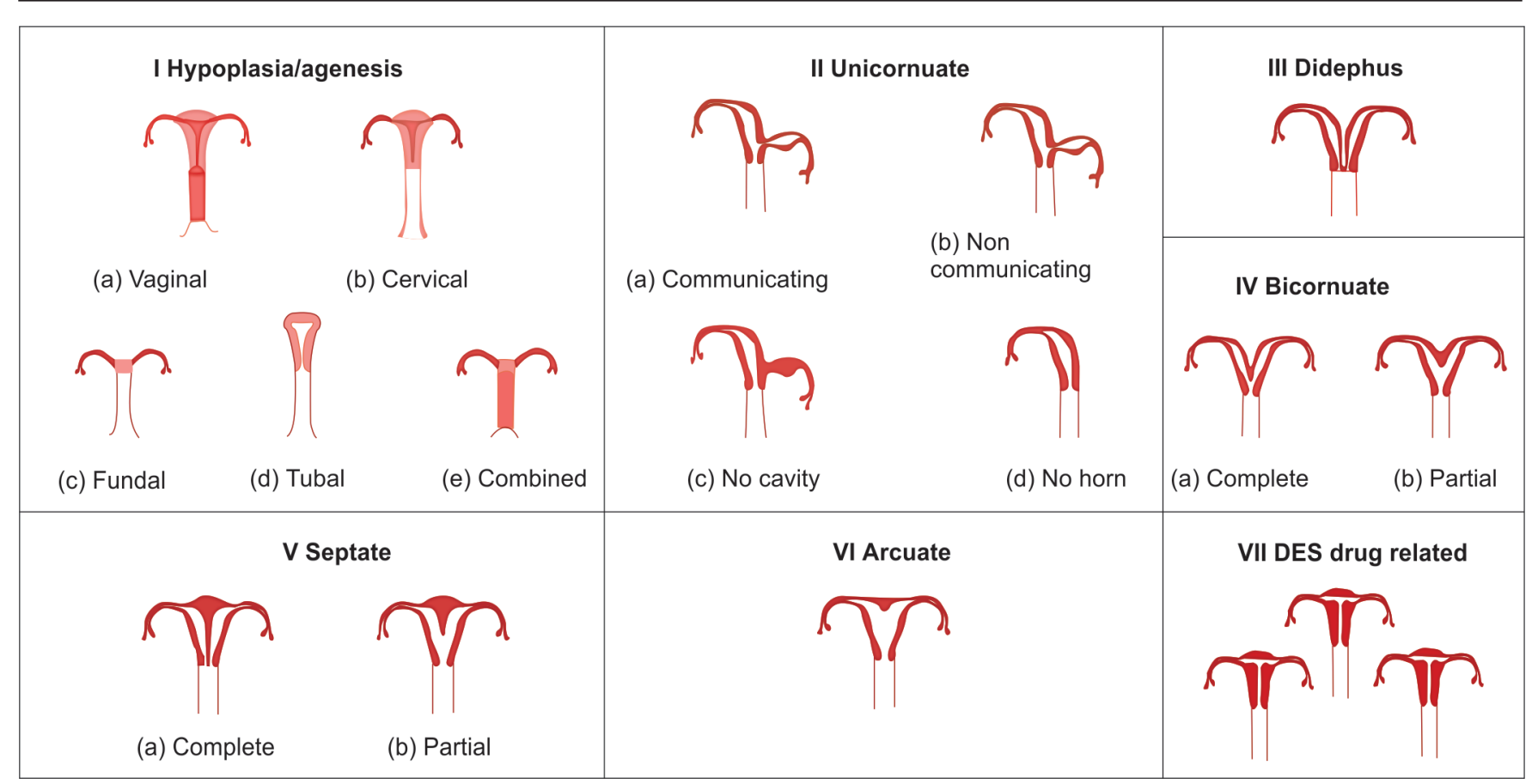

Fig. 1: Classification of congenital uterine anomalies according to the American Fertility Society (1988)

Table 1: Number of cases found during the study period

\begin{tabular}{lll}
\hline Type of anomaly & Number & Total \\
\hline Arcuate & 4 & 4 \\
Bicornuate & 3 & 7 \\
Septate & 2 & 9 \\
Unicornuate & 1 & 10 \\
\hline
\end{tabular}

Table 3: Pregnancy outcome with uterine anomalies

\begin{tabular}{lllll}
\hline & & $27-34$ & $34-37$ & \\
Type of anomalies & PPROM & weeks & weeks & $>37$ weeks \\
\hline Arcuate $(\mathrm{n}=4)$ & 0 & 0 & 0 & $4(100 \%)$ \\
Bicornuate $(\mathrm{n}=03)$ & 2 & 0 & $2(66.6 \%)$ & $1(33.3)$ \\
Septate $(\mathrm{n}=02)$ & 1 & $1(50 \%)$ & $1(50 \%)$ & 0 \\
Unicornuate (01) & 0 & 0 & 0 & $01(100 \%)$ \\
\hline
\end{tabular}

Table 4 shows that 8 women out of 10 underwent cesarean section and only two women had vaginal delivery. This is because of fetal malpresentation, i.e., mostly seen in uterine anomalies.

\section{DISCUSSION}

The early trimester ultrasound scans in our daily clinical work help in diagnosis of uterine anomalies in which more follow-ups are required; deliveries have to be done at higher centers to prevent maternal and fetal complications.

Our results show that arcuate uterus has a good outcome. All women with arcuate uterus have delivered fetus at full term. According to Raga et al, ${ }^{4}$ live birth rate $(82.7 \%)$ of arcuate uterus is higher as compared with other uterine anomalies (bicornuate uterus of $62.5 \%$ and septate uterus of $62 \%$ ).

In bicornuate uterus, two women had preterm delivery and all the women underwent cesarean section, which is
Table 2: Previous pregnancy outcomes with respect to uterine anomalies

\begin{tabular}{lllll}
\hline Type of anomalies & Primi & $\begin{array}{l}\text { Previous } \\
\text { miscarriage }\end{array}$ & $\begin{array}{l}\text { Living } \\
\text { children }\end{array}$ & Total \\
\hline Arcuate $(\mathrm{n}=4)$ & 1 & 2 & 1 & 4 \\
Bicornuate $(\mathrm{n}=03)$ & 0 & 1 & 2 & 3 \\
Septate $(\mathrm{n}=02)$ & 0 & 2 & 00 & 2 \\
Unicornuate $(01)$ & 1 & 0 & 0 & 1 \\
\hline
\end{tabular}

Table 4: Mode of delivery according to type of uterine anomalies

\begin{tabular}{llll}
\hline Type of anomalies & Malpresentation & $\begin{array}{l}\text { Cesarean } \\
\text { section }\end{array}$ & $\begin{array}{l}\text { Vaginal } \\
\text { delivery }\end{array}$ \\
\hline Arcuate $(\mathrm{n}=4)$ & 1 & $2(20 \%)$ & $2(20 \%)$ \\
Bicornuate $(\mathrm{n}=3)$ & 2 & $3(30 \%)$ & 0 \\
Septate $(\mathrm{n}=2)$ & 1 & $2(20 \%)$ & 0 \\
Unicornuate $(1)$ & 1 & $1(10 \%)$ & 0 \\
\hline Total & & $8(80 \%)$ & $2(20 \%)$ \\
\hline
\end{tabular}

due to fetal malpresentation. In the study of Ludmir et al, ${ }^{5}$ it shows that pregnancy beyond 25 weeks of gestation has improved outcomes, but these are associated with high frequency of malpresentation and cesarean delivery. Premature rupture of membrane was high in our study $(100 \%)$. In Hua et $\mathrm{al}^{6}$ study, $7 \%$ of uterine anomalies and $2 \%$ normal uterine morphologies had premature rupture of membranes, with $\mathrm{p}$-value of $<0.1$, which was statistically significant.

Of septate uterus, both women had preterm delivery. According to Kupesic ${ }^{7}$ the thickness of septum has no influence on obstetric complication, but significantly higher prevalence of early pregnancy loss and late complication are seen more in vascularized septum than those with nonvascularized. In septate uterus, Hua et $\mathrm{al}^{6}$ shows $31 \%$ of prematurity and buttram shows $33 \%$ of prematurity and $67 \%$ of miscariages. 
The unicornuate uterus is the most uncommon uterine anomaly; our study had only one unicornute uterus, which went up to term pregnancy with breech presentation and underwent cesarean section.

Ludir et $\mathrm{al}^{5}$ study shows that there is a high rate of pregnancy loss (80\%) in unicornuate uterus.

The limitation of our study is that, as the sample size is small, we cannot draw any inference from our study.

\section{CONCLUSION}

Women with a uterine anomaly are at risk for premature rupture of membranes. This at-risk population needs further study for possible interventions that prevent this process.

\section{REFERENCES}

1. The American Fertility Society classification of adenaxl adhesions, distal tubal occlusion secondary to tubal ligation, Mullerian anomalies, and intra uterine adhesions 1988;49: 944-955.
2. Buttram VC Jr, Gibbons WE. Mullerian anomalies: A proposed classification (an anlaysis of 144 cases). Fertil Steril 1979;32:40-48.

3. Akar ME, Bayar D, Yildiz S, Ozel M, Yilmaz Z. Reproductive outcome of women with unicornuate uterus. Aust N Z J Obstet Gynaecol 2005 Apr;45(2):148-150.

4. Raga F, Bauset C, Remohi J, Bonilla-Musoles F, Simón C, Pellicer A. Reproductive impact of congenital Müllerian anomalies. Hum Reprod 1997 Oct 1;12(10):2277-2281.

5. Ludmir J, Samuels P, Brooks S, Mennuti MT. Pregnancy outcome of patients with uncorrected uterine anomalies managed in a high-risk obstetric setting. Obstet Gynecol 1990 Jun 1;75(6):906-910.

6. Hua M, Odibo AO, Longman RE, Macones GA, Roehl KA, Cahill AG. Congenital uterine anomalies and adverse pregnancy outcomes. Am J Obstet Gynecol 2011 Dec 31;205(6):558. e1-558.e5.

7. Kupesic S. Clinical implications of sonographic detection of uterine anomalies for reproductive outcome. Ultrasound Obstet Gynecol 2001 Oct 1;18(4):387-400.

8. Buttram VC Jr. Müllerian anomalies and their management. Fertil Steril 1983 Aug;40(2):159-163. 
